\title{
Meta-analysis of internal herniation after gastric bypass surgery
}

\author{
N. Geubbels ${ }^{1}$, N. Lijftogt ${ }^{3}$, M. Fiocco ${ }^{4,5}$, N. J. van Leersum ${ }^{3}$, M. W. J. M. Wouters ${ }^{2}$ and \\ L. M. de Brauw ${ }^{1}$ \\ ${ }^{1}$ Department of Metabolic and Bariatric Surgery, Slotervaart Hospital, and ${ }^{2}$ Department of Surgery, Antoni van Leeuwenhoek Hospital, Amsterdam, and \\ ${ }^{3}$ Department of Surgery, ${ }^{4}$ Department of Medical Statistics and Bioinformatics, and ${ }^{5}$ Institute of Mathematics, Leiden University Medical Centre, \\ Leiden, The Netherlands \\ Correspondence to: Ms N. Geubbels, Department of Metabolic and Bariatric Surgery, Slotervaart Hospital, Louwesweg 6, 1066 EC, Amsterdam, The \\ Netherlands (e-mail: ngeubbels@gmail.com)
}

\begin{abstract}
Background: The aim of this study was to provide a systematic and quantitative summary of the association between laparoscopic Roux-en-Y gastric bypass (LRYGB) and the reported incidence of internal herniation (IH). The route of the Roux limb and closure of mesenteric and/or mesocolonic defects are described as factors of influence.

Methods: MEDLINE, Embase, the Cochrane Library and Web of Science were searched for relevant literature, references and citations according to the PRISMA statement. Two independent reviewers selected studies that evaluated incidence of IH after LRYGB and possible techniques for prevention. Data were pooled by route of the Roux limb and closure/non-closure of the mesenteric and/or mesocolonic defects.

Results: Forty-five articles included data on 31320 patients. Lowest IH incidence was in the antecolic group, with closure of all defects ( 1 per cent; $P<0.001)$, followed by the antecolic group, with all defects left open and the retrocolic group with closure of the mesenteric and mesocolonic defect (both 2 per cent; $P<0.001)$. The incidence of IH was highest in the antecolic group, with closure of the jejunal defect, and in the retrocolic group, with closure of all defects (both 3 per cent).

Conclusion: This is the first systematic review on this topic to include a random-effects meta-analysis. The antecolic procedure, with closure of both the mesenteric and Petersen defects, has the lowest IH incidence following LRYGB.
\end{abstract}

Paper accepted 10 November 2014

Published online in Wiley Online Library (www.bjs.co.uk). DOI: 10.1002/bjs.9738

\section{Introduction}

To date, bariatric surgery is the only sustainable solution for reducing weight and co-morbidities in the morbidly obese population ${ }^{1}$. In 2011, 340768 bariatric procedures were performed globally ${ }^{2}$. Laparoscopic Roux-en-Y gastric bypass (LRYGB) is the preferred operation, accounting for approximately 45 per cent of all bariatric procedures ${ }^{2}$. Together with the growing popularity of LRYGB, there has been an increase in the incidence of internal herniation $(\mathrm{IH})^{3}$. IH occurs when small bowel herniates through the defects in the intermesenteric spaces created when the Roux limb is being mobilized to the newly created pouch. Possible sites for IH are the spaces between the mesentery at the jejunojejunostomy (JJ space), the Roux limb and the gastrojejunostomy (Petersen's space), and, in the retrocolic route, the extra defect created in the mesocolon.

$\mathrm{IH}$ is one of the most common complications of LRYGB, with a reported prevalence as high as 14 per cent ${ }^{4}$. The clinical presentation ranges from mild and intermittent abdominal cramping to acute small bowel obstruction (SBO). The most feared complication of $\mathrm{IH}$ is strangulation. SBO is a serious complication, with a reported prevalence $0 \cdot 6-11$ per cent $t^{5}$. It is an emergency that warrants surgical intervention, and is the result of $\mathrm{IH}$ in the majority of cases ${ }^{6}$. SBO is recognizable clinically, but this cannot be said of the more intermittent and subacute clinical presentations of IH. Diagnosis of $\mathrm{IH}$ is usually by abdominal CT, with its variable sensitivity and specificity $^{7,8}$. Two methods to reduce the incidence of $\mathrm{IH}$ 
have been studied extensively: use of the antecolic route for the Roux limb and closure of the mesenteric defects.

The aim of this systematic review was to clarify the actual incidence of IH in antecolic and retrocolic LRYGB populations, and to assess whether closure of the mesenteric defects prevents or reduces the occurrence of IH.

\section{Methods}

\section{Systematic search strategy}

Two specialized librarians and two of the investigators performed a systematic search to identify all relevant studies. Multiple text words and different medical subject headings $(\mathrm{MeSH})$ terms were selected. The search was conducted in the electronic databases MEDLINE (PubMed), Embase and the Cochrane Library. Reference lists of the relevant articles were snowballed, and cited articles were checked using Web of Science to identify additional articles that might have been missed in the original search.

\section{Study selection}

On 19 September 2013, the Cochrane Library, PubMed and Embase were searched using the keywords shown in Table 1. MeSH terms were used to cover the most frequently used synonyms. The two authors performed the literature search independently. Only articles in Dutch and English were selected. Studies were screened using the following inclusion criteria: morbidly obese patients (body mass index above $40 \mathrm{~kg} / \mathrm{m}^{2}$ or greater than $35 \mathrm{~kg} / \mathrm{m}^{2}$ with co-morbidities), age above 18 years and under 65 years, undergoing laparoscopic Roux-en-Y gastric bypass with a well described and standardized surgical technique, size or incidence rate of IH reported. Only studies using primary data (no editorials or systematic reviews) were included.

Articles were selected for closer reading. Articles were excluded when the study population did not meet the above-mentioned requirements, no accurate technique was described or the incidence of $\mathrm{IH}$ was not mentioned. When the same patient cohort was presented in different articles, the most relevant article was used.

Any discrepancies regarding inclusion or exclusion of a study were resolved by discussion with a third investigator.

\section{Data interpretation}

The following outcomes were extracted using a preformatted Excel ${ }^{\mathrm{TM}}$ (Microsoft, Redmond, Washington, USA) sheet: year of publication, sample sizes in both groups, level of evidence with critical appraisal, incidence of $\mathrm{IH}$, the technique used including the material (when available) and
Table 1 Search terms

('Gastric Bypass' [MeSH] OR gastric bypass* OR RYGB OR LRYGB OR roux ${ }^{\star}$ OR gastrojejunostom*) AND (Hernia OR hernia* OR mesenteric defects OR petersen hernia OR jejunostomy hernia OR small bowel obstruction) AND (internal OR antecol* OR retrocol* OR closing intermesenterial spaces) Limits Dutch and English

closure and non-closure of defects, location of the internal hernia, weight loss, time to follow-up and time to occurrence of herniation.

\section{Quality appraisal}

Each of the selected studies was appraised critically according to the PRISMA statement ${ }^{9}$. An assessment of risk of bias and confounding was performed for the included studies. Special items for quality control were: confounding because of incomparable groups, information bias by inadequate outcome measurement, and selection bias by incomplete follow-up.

Final inclusion was decided upon in a consensus meeting. Discrepancies in judgement were resolved by discussion between the investigators. Data were discussed with a statistician.

\section{Statistical analysis}

A random-effects model was employed to pool studyspecific incidences in order to calculate an overall incidence with associated c.i. The inverse-variance method was used to combine outcomes from different studies, as this attributes more weight to larger studies.

Three antecolic and two retrocolic subgroups were created to conduct five separate meta-analyses, owing to the varying nature of the studies. To estimate the between-study variance, represented as $\tau$ (tau) in the forest plots, DerSimonian-Laird's method was employed ${ }^{10}$. All statistical analyses were performed by using $\mathrm{R}$ version $2 \cdot 18$ (http://www.r-project.org) $)^{11}$.

\section{Results}

\section{Included studies}

Using the above-mentioned search terms, 497 publications were identified. After excluding 438 articles, the remaining 59 articles were selected for closer reading. Subsequently, 13 articles did not match the criteria for critical appraisal and one article appeared to be a case report after a thorough search of an international librarian database (Fig. 1). The remaining 45 articles were scrutinized and mined for data (Table S1, supporting information) $)^{3-6,12-52}$. 


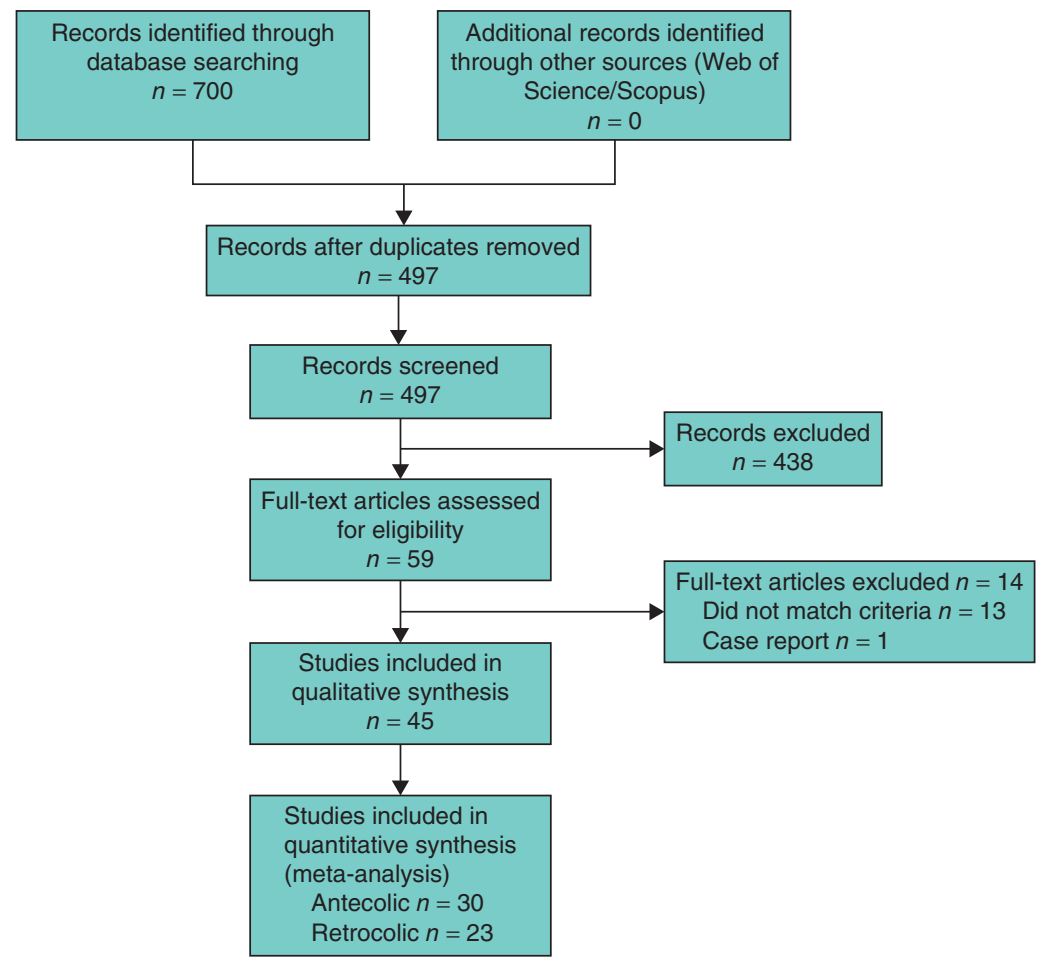

Fig. 1 PRISMA diagram showing selection of articles for review

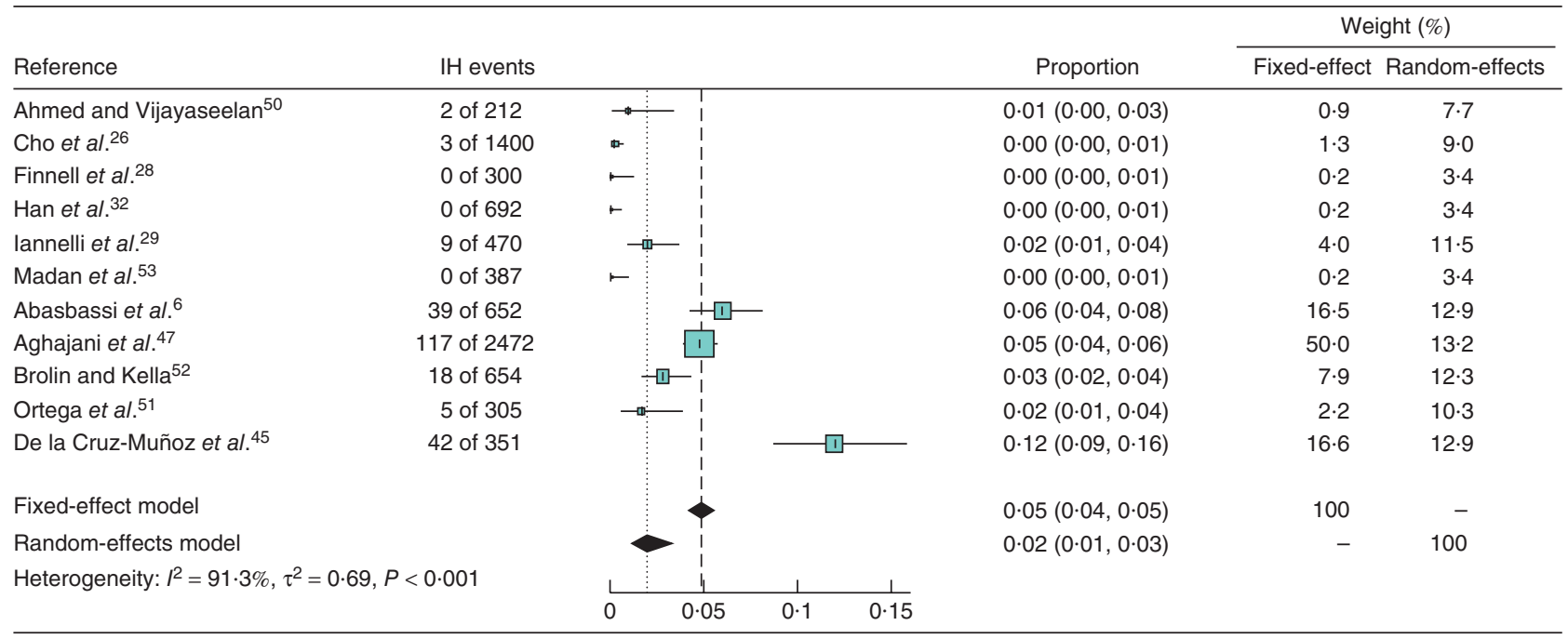

Fig. 2 Forest plot illustrating the incidence of internal herniation (IH) in 11 studies reporting on the antecolic approach with no closure of defects. Number of events was 235 in a total of 7895 patients. Pooled proportions are shown with 95 per cent c.i., calculated using both fixed-effect and random-effects models

\section{Study characteristics}

The 45 papers included 31320 patients (Table S1, supporting information). Most articles concerned observational studies with varying sample sizes, from very small to large multicentre studies. Two low-quality randomized clinical trials ${ }^{22,27}$ included $\mathrm{IH}$ as a secondary outcome measure but did not compare closure versus non-closure of defects. The majority were either case-control studies or poor-quality cohort studies, with level of evidence varying between $2 \mathrm{~b}$ and 4 . Critical appraisal revealed a lack of 


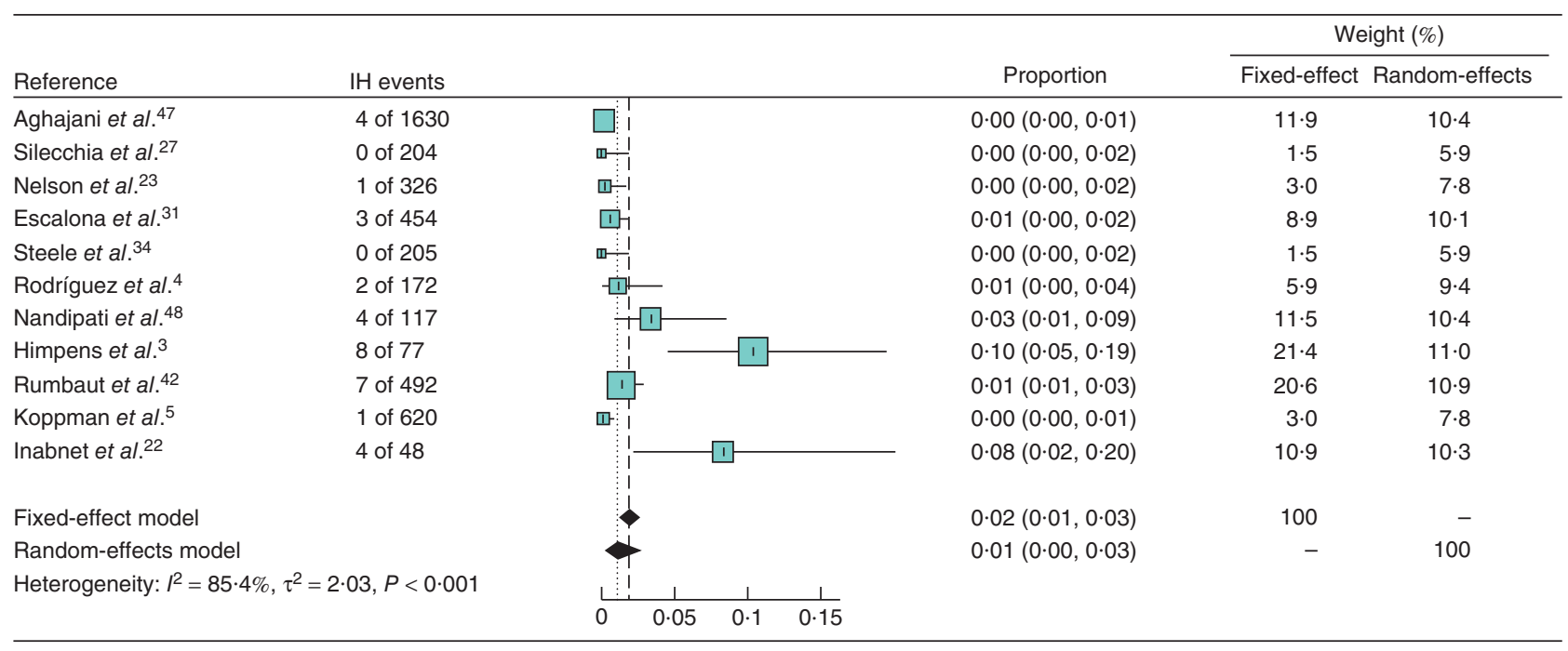

Fig. 3 Forest plot illustrating the incidence of internal herniation (IH) in 11 studies reporting on the antecolic approach with closure of all defects. Number of events was 34 in a total of 4345 patients. Pooled proportions are shown with 95 per cent c.i., calculated using both fixed-effect and random-effects models

\begin{tabular}{|c|c|c|c|c|c|}
\hline \multirow[b]{2}{*}{ Reference } & \multirow[b]{2}{*}{ IH events } & & \multirow[b]{2}{*}{ Proportion } & \multicolumn{2}{|c|}{ Weight (\%) } \\
\hline & & & & Fixed-effect & Random-effects \\
\hline Hope et al. ${ }^{41}$ & 0 of 10 & $\begin{array}{lll}: 1 \\
4\end{array}$ & $0.00(0.00,0.31)$ & 0.2 & $2 \cdot 3$ \\
\hline Gandhi et al. ${ }^{37}$ & 15 of 702 & 가 & $0.02(0.01,0.03)$ & $6 \cdot 6$ & $8 \cdot 1$ \\
\hline Hwang et al. ${ }^{16}$ & 4 of 1310 & m 1 & $0.00(0.00,0.01)$ & $1 \cdot 8$ & $6 \cdot 6$ \\
\hline Quebbemann and Dallal et al. ${ }^{21}$ & 18 of 200 & $1-1$ & $0.09(0.05,0.14)$ & $7 \cdot 4$ & $8 \cdot 1$ \\
\hline Quebbemann and Dallal et al. ${ }^{21}$ & 1 of 200 & $=1$ & $0.00(0.00,0.03)$ & 0.5 & $3 \cdot 8$ \\
\hline Carmody et al. ${ }^{17}$ & 12 of 136 & $+\square-$ & $0.09(0.05,0.15)$ & $5 \cdot 0$ & $7 \cdot 8$ \\
\hline Müller et $a l .^{30}$ & 3 of 33 & 1 & $0.09(0.02,0.24)$ & $1 \cdot 2$ & $5 \cdot 9$ \\
\hline Bauman et al..$^{38}$ & 65 of 1047 & 1. & $0.06(0.05,0.08)$ & $27 \cdot 6$ & $8 \cdot 6$ \\
\hline Gunabushanam et al. ${ }^{36}$ & 14 of 835 & प & $0.02(0.01,0.03)$ & $6 \cdot 2$ & $8 \cdot 0$ \\
\hline Schneider et al. ${ }^{43}$ & 58 of 934 & 1 & $0.06(0.05,0.08)$ & $24 \cdot 6$ & $8 \cdot 6$ \\
\hline lannelli et al. ${ }^{29}$ & 2 of 155 & $\begin{array}{l:l} \\
-\pi\end{array}$ & $0.01(0.00,0.05)$ & 0.9 & $5 \cdot 3$ \\
\hline Brolin and Kella et al. ${ }^{52}$ & 2 of 218 & $\begin{array}{lll}1 & 1 \\
-\pi & 1\end{array}$ & $0.01(0.00,0.03)$ & 0.9 & $5 \cdot 3$ \\
\hline Rodríguez et al. ${ }^{4}$ & 27 of 187 & -1 & $0 \cdot 14(0 \cdot 10,0 \cdot 20)$ & $10 \cdot 5$ & $8 \cdot 3$ \\
\hline Nandipati et al. ${ }^{48}$ & 13 of 325 & $-\square^{-1}$ & $0.04(0.02,0.07)$ & $5 \cdot 7$ & $7 \cdot 9$ \\
\hline De la Cruz-Muñoz et al. ${ }^{45}$ & 2 of 1728 & $\begin{array}{ll} & =1 \\
& 1 \\
& 1\end{array}$ & $0.00(0.00,0.00)$ & 0.9 & $5 \cdot 3$ \\
\hline Fixed-effect model & & 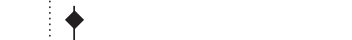 & $0.05(0.05,0.06)$ & 100 & - \\
\hline Random-effects model & & -1 & $0.03(0.02,0.05)$ & - & 100 \\
\hline \multirow{2}{*}{\multicolumn{2}{|c|}{ Heterogeneity: $I^{2}=90.9 \%, \tau^{2}=0.76, P<0.001$}} & 11 & & & \\
\hline & & $\begin{array}{llllllll}0 & 0.05 & 0.1 & 0.15 & 0.2 & 0.25 & 0.3\end{array}$ & & & \\
\hline
\end{tabular}

Fig. 4 Forest plot illustrating the incidence of internal herniation (IH) in 15 studies reporting on the antecolic approach with closure of the mesentery of the jejunojejunostomy defect. Number of events was 236 in a total of 8020 patients. Pooled proportions are shown with 95 per cent c.i., calculated using both fixed-effect and random-effects models

information on follow-up in most studies (Table S1, supporting information). Thirty studies or study arms were analysed in the antecolic section, compared with 23 in the retrocolic section. The incidence of $\mathrm{IH}$ varied between 0 to 16 per cent. In the antecolic group, IH occurred mostly through the JJ mesenteric space, even when it was closed. In the retrocolic groups, IH occurred mostly through the mesocolonic defect if it was left open; if it was closed, IH was mostly through the $\mathrm{JJ}$ mesenteric space. 


\begin{tabular}{|c|c|c|c|c|c|}
\hline \multirow[b]{2}{*}{ Reference } & \multirow[b]{2}{*}{$\mathrm{IH}$ events } & & \multirow[b]{2}{*}{ Proportion } & \multicolumn{2}{|c|}{ Weight (\%) } \\
\hline & & & & Fixed-effect & Random-effects \\
\hline Ahmed and Vijayaseelan et al. ${ }^{50}$ & 54 of 2215 & $1-1$ & $0.02(0.02,0.03)$ & $29 \cdot 1$ & $12 \cdot 4$ \\
\hline Nguyen et al. ${ }^{14}$ & 3 of 225 & $\begin{array}{l:l}1 \\
-1\end{array}$ & $0.01(0.00,0.04)$ & $1 \cdot 6$ & $7 \cdot 4$ \\
\hline Carmody et al. ${ }^{17}$ & 3 of 542 & $-\square-$ & $0.01(0.00,0.02)$ & $1 \cdot 7$ & $7 \cdot 4$ \\
\hline Marema et al. ${ }^{19}$ & 18 of 1077 & $-\square-1$ & $0.02(0.01,0.03)$ & $9 \cdot 8$ & $11 \cdot 5$ \\
\hline Eckhauser et al. ${ }^{24}$ & 13 of 529 & -1 & $0.02(0.01,0.04)$ & $7 \cdot 0$ & $11 \cdot 0$ \\
\hline Escalona et al. ${ }^{31}$ & 24 of 300 & $1-1$ & $0.08(0.05,0.12)$ & $12 \cdot 2$ & $11 \cdot 8$ \\
\hline Han et al..$^{32}$ & 8 of 143 & $\begin{array}{l}1 \\
+\end{array}$ & $0.06(0.02,0.11)$ & $4 \cdot 2$ & $10 \cdot 0$ \\
\hline Steele et al. ${ }^{34}$ & 7 of 274 & $-\frac{1}{1}$ & $0.03(0.01,0.05)$ & $3 \cdot 8$ & $9 \cdot 8$ \\
\hline Paroz et al. ${ }^{39}$ & 57 of 1015 & -1 & $0.06(0.04,0.07)$ & $29 \cdot 8$ & $12 \cdot 4$ \\
\hline Miyashiro et al. ${ }^{40}$ & 0 of 847 & $\leftarrow$ & $0.00(0.00,0.00)$ & 0.3 & $2 \cdot 4$ \\
\hline Agrawal ${ }^{44}$ & 1 of 74 & $\longrightarrow$ & $0.01(0.00,0.07)$ & 0.5 & $4 \cdot 0$ \\
\hline Fixed-effect model & & 1 & $0.03(0.03,0.04)$ & 100 & - \\
\hline Random-effects model & & & $0.03(0.02,0.04)$ & - & 100 \\
\hline \multirow{2}{*}{\multicolumn{2}{|c|}{ Heterogeneity: $I^{2}=86.6 \%, \tau^{2}=0.45, P<0.001$}} & $\begin{array}{lllll}1 & 1 & \\
1 & 1 & 1 & 1 \\
& 1 & 1\end{array}$ & & & \\
\hline & & $\begin{array}{lllllllllllll}0 & 0.02 & 0.04 & 0.06 & 0.08 & 0.1\end{array}$ & & & \\
\hline
\end{tabular}

Fig. 5 Forest plot illustrating the incidence of internal herniation (IH) in 11 studies reporting on the retrocolic approach with closure of all defects. Number of events was 188 in a total of 7241 patients. Pooled proportions are shown with 95 per cent c.i., calculated using both fixed-effect and random-effects models

\begin{tabular}{|c|c|c|c|c|c|}
\hline \multirow[b]{2}{*}{ Reference } & \multirow[b]{2}{*}{ IH events } & & \multirow[b]{2}{*}{ Proportion } & \multicolumn{2}{|c|}{ Weight (\%) } \\
\hline & & & & Fixed-effect & Random-effects \\
\hline Filip et al. ${ }^{12}$ & 5 of 100 & : ए & $0.05(0.02,0.11)$ & $5 \cdot 2$ & $14 \cdot 0$ \\
\hline Hwang et al..$^{16}$ & 13 of 405 & $\square \quad 1$ & $0.03(0.02,0.05)$ & $13 \cdot 9$ & $15 \cdot 4$ \\
\hline Onopchenko et al. ${ }^{18}$ & 5 of 185 & \begin{tabular}{l|l} 
& 1 \\
\end{tabular} & $0.03(0.01,0.06)$ & $5 \cdot 4$ & $14 \cdot 1$ \\
\hline Nelson et al. ${ }^{23}$ & 2 of 326 & $-\square$ & $0.01(0.00,0.02)$ & $2 \cdot 2$ & $11 \cdot 7$ \\
\hline Capella et al. ${ }^{25}$ & 61 of 697 & & $0.09(0.07,0.11)$ & $61 \cdot 4$ & $16 \cdot 2$ \\
\hline Parakh et al. ${ }^{33}$ & 6 of 290 & \multirow{2}{*}{ —ा } & $0.02(0.01,0.04)$ & $6 \cdot 5$ & $14 \cdot 4$ \\
\hline Kissane et al. ${ }^{46}$ & 5 of 1262 & & $0.00(0.00,0.01)$ & $5 \cdot 5$ & $14 \cdot 1$ \\
\hline \multicolumn{3}{|l|}{ Fixed-effect model } & $0.05(0.04,0.06)$ & 100 & - \\
\hline \multicolumn{3}{|c|}{ Random-effects model } & $0.02(0.01,0.05)$ & - & 100 \\
\hline \multirow{2}{*}{\multicolumn{3}{|c|}{ Heterogeneity: $I^{2}=91.7 \%, \tau^{2}=1.23, P<0.001$}} & & & \\
\hline & & & & & \\
\hline
\end{tabular}

Fig. 6 Forest plot illustrating the incidence of internal herniation (IH) in seven studies reporting on the retrocolic approach with closure of the mesentery, jejunojejunostomy and mesocolic defects. Number of events was 97 in a total of 3265 patients. Pooled proportions are shown with 95 per cent c.i., calculated using both fixed-effect and random-effects models

Reported mean or median time to event was 1 day to 108 months. Follow-up data were not reported in 23 studies, predominantly in the retrocolic groups. Reported follow-up ranged from 0 months to 11 years. There were no differences in the reported follow-up data between the antecolic and retrocolic groups. Further analysis of follow-up duration was not possible owing to differences in reporting (mean/median) and the absence of reported follow-up for separate groups (antecolic/retrocolic and closure/non-closure). Weight loss was not reported in the majority of studies.

\section{Meta-analysis}

The incidence of IH associated with each study are presented in forest plots (Figs 2-6). The lowest IH incidence was in the antecolic group with closure of all defects ( 1 per cent; $P<0.001$ ), followed by the antecolic group with all defects left open and the retrocolic group with closure of the mesenteric and mesocolonic defect (both 2 per cent; $P<0.001$ ). IH incidence was highest in the antecolic group with closure of the jejunal defect and the retrocolic group with closure of all defects (both 3 per cent). An overall test for heterogeneity between 
studies was performed for each meta-analysis and gave consistently significant results ( $I^{2}$ value in Figs 2-6).

\section{Discussion}

There is wide variation in the reported incidence of IH, which may occur many years after LRYGB. Therefore, to make a valid estimation of the true incidence of IH, large sample size and long-term follow-up are needed. Both types of data are lacking in the current literature. In an attempt to overcome these shortcomings, this meta-analysis pooled all included studies according to the most frequently cited factors predisposing to the development of IH: the route of the Roux limb and closure/non-closure of the mesenteric defect and/or Petersen's space. The incidence of IH was lowest (1 per cent) in the antecolic group with closure of mesenteric and Petersen defects. The present data are in accordance with the general belief of 94 per cent of American Society for Metabolic and Bariatric Surgery survey responders that at least one mesenteric defect should be closed ${ }^{53}$. However, 35 per cent of these responders still use the retrocolic route.

In the present meta-analysis, outcomes in the retrocolic groups (IH incidence 3 per cent with all defects closed and 2 per cent when only the mesocolonic defect was closed) were inferior to those in the antecolic group with closure of all defects (IH incidence 1 per cent), but similar to outcomes in the antecolic groups with all defects left open (IH incidence 2 per cent) and those with only the mesenteric defect closed (IH incidence 3 per cent). The difference in IH incidence between the pooled groups is small but statistically distinguishable. In view of the large number of patients undergoing LRYGB annually worldwide, the present authors believe them to be clinically relevant as well. This review found an $\mathrm{IH}$ incidence of 2 per cent in the antecolic group with the defects left open and 3 per cent in the antecolic group with the JJ mesenteric defect closed. In theory, the closure of more defects should lead to a lower incidence of $\mathrm{IH}$, although this rationale is not supported by the present meta-analysis.

Closure patency is dependent on several factors, such as surgical skill and the technique used. Furthermore, closure of the mesenteric and/or Petersen defect is no guarantee of sustained closure. In a small study by Hope and colleagues $^{41}, 15$ of 18 patients had open mesenteric or mesocolonic defects on relaparoscopy, despite primary closure. Other large-scale studies ${ }^{13,20,54,55}$ have also addressed this drawback in assessing the effectiveness of closure. As discussed below, closure can in itself lead to the formation of IH. The detection of IH relies largely on the quality, length and completeness of follow-up.
The quality of the included studies was low, generally level 3 or 4 . The only two included randomized trials ${ }^{27,56}$ did not investigate $\mathrm{IH}$ as a primary endpoint. Studies frequently lacked information on time-to-event. Half of the included studies, mostly applying the retrocolic technique, lacked information on follow-up. This could certainly lead to an underestimation of reported $\mathrm{IH}$ incidence in the included studies. Wheeler and co-workers ${ }^{57}$ performed a cross-sectional study of 375 bariatric surgical patients, of whom 50 per cent were defaulting their follow-up appointments only 1 year after surgery. In the present meta-analysis, most authors reported implementation of the antecolic technique and closure of the mesenteric and/or Petersen defect following the discovery of $\mathrm{IH}$ in patients in whom the retrocolic route was used, and in those without closure. As follow-up is usually longer in retrocolic/open groups, the present results might be biased in favour of the antecolic and closure groups.

There is, beyond doubt, an issue with diagnosing as well as defining IH. Twelve studies ${ }^{12,17,18,20,21,26,34,38-40,43,45}$ selected patients based on clinical signs of IH. This is, in the present authors' opinion, the preferred method of selecting patients for relaparoscopy. Twelve studies $^{4-6,23-25,29,33,37,42,51,52}$ selected candidates for relaparoscopy based on clinical signs of SBO. Signs and symptoms of $\mathrm{IH}$ and SBO may overlap, but they are dissimilar. SBO is considered a surgical emergency with a high mortality risk, and has explicit clinical symptoms ${ }^{23}$, whereas $\mathrm{IH}$ often presents with mild and intermittent complaints. Moreover, intestinal gangrene can very well exist without SBO. Studies selecting on signs of SBO might therefore underestimate the true rate of $\mathrm{IH}$. Another possible source of underestimation originates from studies that performed relaparoscopy based only on positive imaging studies. CT was found to have low sensitivity and a large number of false-negative findings in a recent study by Obeid et al..$^{5}$. The most distinct radiological finding in patients with $\mathrm{IH}$ is the swirled appearance of the mesenteric vessels, the so-called 'whirlpool sign'. When the whirlpool sign is present, the specificity of CT for IH diagnosis is increased from 70 to 100 per cent, although sensitivity remains low $(0-44 \text { per cent })^{59}$. Only two studies ${ }^{36,46}$ used radiodiagnostic findings to select patients for relaparoscopy, so the bias resulting from this selection process is probably not substantial. The most common definition of IH is: 'the presence of herniated bowel through one or both of the intermesenteric spaces', and the standard for diagnosis is (re)laparoscopy.

All IHs in the articles included here were diagnosed by means of relaparoscopy. Theoretically, not every herniation of bowel through a mesenteric and/or Petersen space 
results in kinking and obstruction; some simply 'slip back' into place, with concomitant relief of complaints. This fits very well the intermittent pattern of complaints reported by many patients. Few studies have addressed this issue. Aghajani and colleagues ${ }^{47}$ reported 43 patients with intermittent IH. Madan et al. ${ }^{35}$ report a 'potential defect' behind the Roux limb in two of 54 patients who had relaparoscopy; these patients were symptom-free after closure of these defects, but were not included as having intermittent $\mathrm{IH}$ in the IH incidence rate. To strengthen the accuracy of an IH diagnosis, the present authors believe that postoperative remission of complaints should be included as an endpoint in every study on IH.

Also of interest are IHs found incidentally at relaparoscopies conducted for indications other than suspicion of IH. Only four studies ${ }^{21,24,39,48}$ included incidentally found IHs in their series. Ideally, every patient with a clinical suspicion of IH should be offered relaparoscopy. However, most authors employed a low threshold for (re)laparoscopy; only Gandhi and co-workers ${ }^{37}$ mentioned they had offered relaparoscopy to every patient with clinical suspicion of IH. The present analysis shows, however, that the selection criteria for relaparoscopy and the definition of IH employed in the included studies were not optimal, although they were similar in most of the studies.

Mesenteric closure is technically difficult and can be time-consuming and laborious. Suturing the defects is not without risk. Several authors mentioned tearing of the mesentery and subsequent bleeding ${ }^{29,60}$ or tension to the gastrojejunostomy or jejunojejunostomy as a result of the suturing ${ }^{35}$. Himpens etal. ${ }^{3}$ reported that their non-absorbable sutures had 'cut through the tissue' and that 'both defects had reopened'. Absorbable sutures might cause adhesions, which might lead to $\mathrm{SBO}^{24,35}$. Aghajani and colleagues ${ }^{47}$ used a stapling device to close the defects. The proposed advantage of this technique over suturing is that stapling is less time-consuming and easier to perform. Nevertheless, four patients $(0 \cdot 2$ per cent) required reoperation for bowel obstruction caused by the staples ${ }^{47}$. Opponents to closure of defects argue that closure produces small holes in the mesentery or mesocolon, which might increase the risk of bowel herniation. Increased operating time and cost are other arguments in favour of non-closure ${ }^{16,51}$.

Suturing of the intermesenteric spaces was the preferred method of closure in the majority (30 of 39) of the included

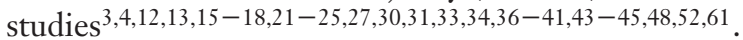

Non-absorbable sutures were used in 25 studies, in a running fashion in 16 studies $3,4,13,16,17,22,31,34,37,38,40,41,45,48,52,61$. In five studies ${ }^{4,18,24,31,39}$ the method of closure was changed during the course of the study, generally from absorbable to non-absorbable material. These changes often also involved a change in Roux limb orientation or the closure of an intermesenteric space, making conclusions hard to draw. The closure technique reported by Aghajani etal. ${ }^{47}$ is promising and involves the stapling of the intermesenteric spaces. The additional operating time needed for suturing of the intermesenteric defects was not available for any of the included studies, although the general consensus was that this suturing is difficult and time-consuming. Aghajani and colleagues ${ }^{47}$ recorded a mean extra time of $1 \mathrm{~min} 49 \mathrm{~s}$ (range from $1 \mathrm{~min} 20 \mathrm{~s}$ to $2 \mathrm{~min} 50 \mathrm{~s}$ ) for the stapling of the intermesenteric spaces.

Rapid weight loss has been associated with $\mathrm{IH}^{37,43,62}$. Such weight loss results in a quick reduction of the intra-abdominal fat mass, which is unable to heal in that short time interval ${ }^{24,30,43}$. Unfortunately, only 18 of the studies included weight loss in their results. The method of reporting weight loss varied: some studies reported the percentage excess weight loss (\%EWL), whereas others reported the net BMI unit loss at a fixed time point. Unfortunately, the diversity in reporting weight loss was too great for this factor to be included in the present meta-analysis.

Other factors predisposing to the development of $\mathrm{IH}$ include: division of the jejunal mesentery ${ }^{28,35}$, placement of an antiobstruction stitch ${ }^{52}$, anticlockwise rotation of the Roux limb ${ }^{48}$, and left or right Roux limb configuration ${ }^{21}$. Studies addressing these factors were too few to be included in the meta-analysis. These factors may well be the cause of the high level of heterogeneity observed in all meta-analysis groups.

There are two ongoing randomized clinical trials whose results may have substantial influence on the understanding of IH. The first is a Swedish trial (NCT01137201) that randomized 2508 patients to closure of the intermesenteric defects with running, non-absorbable suture or to leaving the defects open. The primary outcome measure is surgery for SBO measured within a 2-year time frame. The second study of interest is a Danish study (NCT01595230) that is currently enrolling patients. Five hundred patients will be randomized between closure of the intermesenteric defects with staples and leaving the defects open. The primary outcome is IH development after 5 years of follow-up. The complexities highlighted by the present systematic review - insufficient data on follow-up, absence of a clear selection algorithm and $\mathrm{IH}$ definition, and information on confounding factors such as closure technique, material and postoperative weight loss - will be addressed fully in these studies.

To date, this is the only systematic review to include a meta-analysis on IH. The incidence of IH was lowest (1 per cent) in the group with antecolic placement of the Roux 
limb and closure of mesenteric and Petersen defects. There may be bias owing to the lack of follow-up data, differences in follow-up duration favouring the antecolic and closure groups, and lack of data concerning possible predisposing factors such as postoperative weight loss, antiobstruction stitches and configuration of the Roux limb. Closure of the defects has been reported to be harmful in some cases, and there is no guarantee the defect remains closed. Prospective randomized clinical trials evaluating various techniques of closure with adequate length and quality of follow-up are needed urgently to assess the true incidence rate of $\mathrm{IH}$, evaluate the effect of closure, and reach consensus on the preferred method of closure.

\section{Acknowledgements}

N.G. and N.L. are joint first authors of this article. The authors acknowledge $W$. te Riele for his help in designing this study and providing guidance on several issues. They also acknowledge C. Sloof and W. Schats for their help with the systematic literature search and determining duplication of articles.

Disclosure: The authors declare no conflict of interest.

\section{References}

1 Sjöström L, Lindroos AK, Petlonen M, Torgerson J, Bouchard C, Carlsson B etal. Lifestyle, diabetes, and cardiovascular risk factors 10 years after bariatric surgery. N Engl 7 Med 2004; 351: 2683-2693.

2 Buchwald H, Oien DM. Metabolic/bariatric surgery worldwide 2011. Obes Surg 2013; 23: 427-436.

3 Himpens J, Verbrugghe A, Cadière G-B, Everaerts W, Greve JW. Long-term results of laparoscopic Roux-en-Y gastric bypass: evaluation after 9 years. Obes Surg 2012; 22: 1586-1593.

4 Rodríguez A, Mosti M, Sierra M, Pérez-Johnson R, Flores S, Dominguez $\mathrm{G}$ et al. Small bowel obstruction after antecolic and antegastric laparoscopic Roux-en-Y gastric bypass: could the incidence be reduced? Obes Surg 2010; 20: 1380-1384.

5 Koppman JS, Li C, Gandsas A. Small bowel obstruction after laparoscopic Roux-en-Y gastric bypass: a review of 9527 patients. 7 Am Coll Surg 2008; 206: 571-584.

6 Abasbassi M, Pottel H, Deylgat B, Vansteenkiste F, Van Rooy F, Devriendt D etal. Small bowel obstruction after antecolic antegastric laparoscopic Roux-en-Y gastric bypass without division of small bowel mesentery: a single-centre, 7-year review. Obes Surg 2011; 21: 1822-1827.

7 Blachar A, Federle MP. Gastrointestinal complications of laparoscopic Roux-en-Y gastric bypass surgery in patients who are morbidly obese: findings on radiography and CT. A7R Am 7 Roentgenol 2002; 179: 1437-1442.

8 Garza E, Kuhn J, Arnold D, Nicholson W, Reddy S, McCarty T. Internal hernias after laparoscopic Roux-en-Y gastric bypass. Am 7 Surg 2004; 188: 796-800.
9 Moher D, Liberati A, Tetzlaff J, Altman DG; PRISMA Group. Preferred reporting items for systematic reviews and meta-analyses: the PRISMA statement. BMF 2009; 339: $332-336$.

10 DerSimonian R, Laird N. Meta-analysis in clinical trials. Control Clin Trials 1986; 7: 177-188.

$11 \mathrm{R}$ Development Core Team. R: A Language and Environment for Statistical Computing. R Foundation for Statistical Computing: Vienna, 2008.

12 Filip J, Mattar S, Bowers S, Smith C. Internal hernia formation after laparoscopic Roux-en-Y gastric bypass for morbid obesity. Am 7 Surg 2002; 7: 640-643.

13 Champion JK, Williams M. Small bowel obstruction and internal hernias after laparoscopic Roux-en-Y gastric bypass. Obes Surg 2003; 13: 596-600.

14 Nguyen NT, Huerta S, Gelfand D, Stevens CM, Jim J, Nguyen NT et al. Bowel obstruction after laparoscopic Roux-en-Y gastric bypass. Obes Surg 2004; 14: 190-196.

15 Felsher J, Brodsky J, Brody F. Small bowel obstruction after laparoscopic Roux-en-Y gastric bypass. Surgery 2003; 134: 501-505.

16 Hwang RF, Swartz DE, Felix EL. Causes of small bowel obstruction after laparoscopic gastric bypass. Surg Endosc 2004; 18: 1631-1635.

17 Carmody B, DeMaria EJ, Jamal M, Johnson J, Carbonell A, Kellum J et al. Internal hernia after laparoscopic Roux-en-Y gastric bypass. Surg Obes Relat Dis 2005; 1: 543-548.

18 Onopchenko A. Radiological diagnosis of internal hernia after Roux-en-Y gastric bypass. Obes Surg 2005; 15 : 606-611.

19 Marema RT, Perez M, Buffington CK. Comparison of the benefits and complications between laparoscopic and open Roux-en-Y gastric bypass surgeries. Surg Endosc 2005; 19: 525-530.

20 Comeau E, Gagner M, Inabnet WB, Herron DM, Quinn TM, Pomp A. Symptomatic internal hernias after laparoscopic bariatric surgery. Surg Endosc 2005; 19: 34-39.

21 Quebbemann BB, Dallal RM. The orientation of the antecolic Roux limb markedly affects the incidence of internal hernias after laparoscopic gastric bypass. Obes Surg 2005; 15: 766-770.

22 Inabnet $W$, Quinn T, Gagner M, Urban M, Pomp A. Laparoscopic Roux-en-Y gastric bypass in patients with $\mathrm{BMI}<50$ : a prospective randomized trial comparing short and long limb lengths. Obes Surg 2005; 15: 51-57.

23 Nelson LG, Gonzalez R, Haines K, Gallagher SF, Murr MM. Spectrum and treatment of small bowel obstruction after Roux-en-Y gastric bypass. Surg Obes Relat Dis 2006; 2: $377-383$

24 Eckhauser A, Torquati A, Youssef Y, Kaiser JL, Richards WO. Internal hernia: postoperative complication of Roux-en-Y gastric bypass surgery. Am Surg 2006; 72: 581-584.

25 Capella RF, Lannace VA, Capella JF. Bowel obstruction after open and laparoscopic gastric bypass surgery for morbid obesity. 7 Am Coll Surg 2006; 203: 328-335. 
26 Cho M, Pinto D, Carrodeguas L, Lascano C, Soto F, Whipple $\mathrm{O}$ et al. Frequency and management of internal hernias after laparoscopic antecolic antegastric Roux-en-Y gastric bypass without division of the small bowel mesentery or closure of mesenteric defects: review of 1400 consecutive cases. Surg Obes Relat Dis 2006; 2: 87-91.

27 Silecchia G, Boru CE, Mouiel J, Rossi M, Anselmino M, Tacchino RM et al. Clinical evaluation of fibrin glue in the prevention of anastomotic leak and internal hernia after laparoscopic gastric bypass: preliminary results of a prospective, randomized multicenter trial. Obes Surg 2006; 16: $125-131$.

28 Finnell CW, Madan AK, Tichansky DS, Ternovits C, Taddeucci R. Non-closure of defects during laparoscopic Roux-en-Y gastric bypass. Obes Surg 2007; 17: 145-148.

29 Iannelli A, Buratti MS, Novellas S, Dahman M, Amor IB, Sejor E etal. Internal hernia as a complication of laparoscopic Roux-en-Y gastric bypass. Obes Surg 2007; 17: $1283-1286$.

30 Müller MK, Guber J, Wildi S, Guber I, Clavien P-A, Weber M. Three-year follow-up study of retrocolic versus antecolic laparoscopic Roux-en-Y gastric bypass. Obes Surg 2007; 17: 889-893.

31 Escalona A, Devaud N, Pérez G, Crovari F, Boza C, Viviani $\mathrm{P}$, et al. Antecolic versus retrocolic alimentary limb in laparoscopic Roux-en-Y gastric bypass: a comparative study. Surg Obes Relat Dis 2007; 3: 423-427.

32 Han S, Gracia C, Mehran A, Basa N, Hines J, Suleman L et al. Improved outcomes using a systematic and evidence-based approach to the laparoscopic Roux-en-Y gastric bypass in a single academic institution. Am Surg 2007; 73: 955-958.

33 Parakh S, Soto E, Merola S. Diagnosis and management of internal hernias after laparoscopic gastric bypass. Obes Surg 2007; 17: 1498-1502.

34 Steele KE, Prokopowicz GP, Magnuson T, Lidor A, Schweitzer M. Laparoscopic antecolic Roux-en-Y gastric bypass with closure of internal defects leads to fewer internal hernias than the retrocolic approach. Surg Endosc 2008; 22: 2056-2061.

35 Madan AK, Lo Menzo E, Dhawan N, Tichansky DS. Internal hernias and nonclosure of mesenteric defects during laparoscopic Roux-en-Y gastric bypass. Obes Surg 2009; 19: $549-552$.

36 Gunabushanam G, Shankar S, Czerniach DR, Kelly JJ, Perugini RA. Small-bowel obstruction after laparoscopic Roux-en-Y gastric bypass surgery. 7 Comput Assist Tomogr 2009; 33: 369-375.

37 Gandhi AD, Patel RA, Brolin RE. Elective laparoscopy for herald symptoms of mesenteric/internal hernia after laparoscopic Roux-en-Y gastric bypass. Surg Obes Relat Dis 2009; 5: 144-149.

38 Bauman RW, Pirrello JR. Internal hernia at Petersen's space after laparoscopic Roux-en-Y gastric bypass: $6 \cdot 2 \%$ incidence without closure - a single surgeon series of 1047 cases. Surg Obes Relat Dis 2009; 5: 565-570.
39 Paroz A, Calmes JM, Romy S, Giusti V, Suter M. A new type of internal hernia after laparoscopic Roux-en-Y gastric bypass. Obes Surg 2009; 19: 527-530.

40 Miyashiro LA, Fuller WD, Ali MR. Favorable internal hernia rate achieved using retrocolic, retrogastric alimentary limb in laparoscopic Roux-en-Y gastric bypass. Surg Obes Relat Dis 2010; 6: 158-162.

41 Hope WW, Sing RF, Chen AY, Lincourt AE, Gersin KS, Kuwada TS etal. Failure of mesenteric defect closure after Roux-en-Y gastric bypass. FSLS 2010; 14: 213-216.

42 Rumbaut R, Merino R, Guajardo H, Sherwell S. Bowel obstruction in bariatric surgery: experience in 500 patients after Roux-en-Y gastric bypass. Obes Surg Conf Publ 2010; 20: 995.

43 Schneider C, Cobb W, Scott J, Carbonell A, Myers K, Bour E. Rapid excess weight loss following laparoscopic gastric bypass leads to increased risk of internal hernia. Surg Endosc 2011; 25: 1594-1598.

44 Agrawal S. Impact of bariatric fellowship training on perioperative outcomes for laparoscopic Roux-en-Y gastric bypass in the first year as consultant surgeon. Obes Surg 2011; 21 : 1817-1821.

45 De la Cruz-Muñoz N, Cabrera JC, Cuesta M, Hartnett S, Rojas R. Closure of mesenteric defect can lead to decrease in internal hernias after Roux-en-Y gastric bypass. Surg Obes Relat Dis 2011; 7: 176-180.

46 Kissane N, Choy G, Gee D, Hutter M, Rattner D, Pratt J. Triad of trouble: CT finding to help diagnose internal hernia post gastric bypass. Surg Endosc 2011; 25: 241-372.

47 Aghajani E, Jacobsen HJ, Nergaard BJ, Hedenbro JL, Leifson BG, Gislason H. Internal hernia after gastric bypass: a new and simplified technique for laparoscopic primary closure of the mesenteric defects. 7 Gastrointest Surg 2012; 16: 641-645.

48 Nandipati KC, Lin E, Husain F, Srinivasan J, Sweeney JF, Davis SS. Counterclockwise rotation of Roux-en-Y limb significantly reduces internal herniation in laparoscopic Roux-en-Y gastric bypass (LRYGB). 7 Gastrointest Surg 2012; 16: 675-681.

49 Bellini F, Pizzi P. The gastric by pass: how I do it. Obes Surg 2012; 22: 1315-1419.

50 Ahmed A, Vijayaseelan T. Do we really need to close internal hernia spaces. Obes Surg Conf Publ 2012; 22: $1330-1331$.

51 Ortega J, Cassinello N, Sánchez-Antúnez D, Sebastián C, Martínez-Soriano F. Anatomical basis for the low incidence of internal hernia after a laparoscopic Roux-en-Y gastric bypass without mesenteric closure. Obes Surg 2013; 23 : $1273-1280$.

52 Brolin RE, Kella VN. Impact of complete mesenteric closure on small bowel obstruction and internal mesenteric hernia after laparoscopic Roux-en-Y gastric bypass. Surg Obes Relat Dis 2013; 9: 1-5.

53 Madan AK, Harper JL, Tichansky DS. Techniques of laparoscopic gastric bypass: on-line survey of American 
Society for Bariatric Surgery practicing surgeons. Surg Obes Relat Dis 2008; 4: 166-172.

54 Higa K, Ho T, Boone K. Internal hernias after laparoscopic Roux-en- $Y$ gastric bypass: incidence, treatment and prevention. Obes Surg 2003; 13: 350-354.

55 Higa KD, Boone KB, Ho T. Complications of the laparoscopic Roux-en-Y gastric bypass: 1040 patients - what have we learned? Obes Surg 2000; 10: 509-513.

56 Inabnet WB III, Belle SH, Bessler M, Dellinger P, Garcia L, Mitchell $\mathrm{J}$ et al. A comparison of 30 day outcomes after non-LapBand primary and revisional bariatric surgical procedures from the Longitudinal Assessment of Bariatric Surgery study. Surg Obes Relat Dis 2010; 6: 22-30.

57 Wheeler E, Prettyman A, Lenhard MJ, Tran K. Adherence to outpatient program postoperative appointments after bariatric surgery. Surg Obes Relat Dis 2008; 4: 515-520.

58 Obeid A, McNeal S, Breland M, Stahl R, Clements RH,
Grams J. Internal hernia after laparoscopic Roux-en-Y gastric bypass. 7 Gastrointest Surg 2014; 18 : $250-255$.

59 Iannuccilli JD, Grand D, Murphy BL, Evangelista P, Roye GD, Mayo-Smith W. Sensitivity and specificity of eight CT signs in the preoperative diagnosis of internal mesenteric hernia following Roux-en-Y gastric bypass surgery. Clin Radiol 2009; 64: 373-380.

60 Coleman MH, Awad ZT, Pomp A, Gagner M. Laparoscopic closure of the Petersen mesenteric defect. Obes Surg 2006; 16: 770-772.

61 Iannelli A, Facchiano E, Gugenheim J. Internal hernia after laparoscopic Roux-en-Y gastric bypass for morbid obesity. Obes Surg 2006; 16: 1265-1271.

62 Paroz A, Calmes JM, Giusti V, Suter M. Internal hernia after laparoscopic Roux-en-Y gastric bypass for morbid obesity: a continuous challenge in bariatric surgery. Obes Surg 2006; 16: 1482-1487.

\section{Supporting information}

Additional supporting information may be found in the online version of this article:

Table S1 Study characteristics and critical appraisal of included studies (Word document) 